\title{
Late onset form of Pompe disease
}

\author{
Mattosova $\mathrm{S}^{1,4}$, Hlavata $\mathrm{A}^{2}$, Spalek $\mathrm{P}^{3}$, Kotysova $\mathrm{L}^{1,4}$, Macekova $\mathrm{D}^{1}$, Chandoga $\mathrm{J}^{1}$ \\ Institute of Medical Biology, Genetics and Clinical Genetics, Comenius University Faculty of Medicine, \\ University Hospital, Bratislava, Slovakia. smattosova@gmail.com
}

\begin{abstract}
BACKGROUND: Pompe disease is an autosomal recessive disorder of glycogen metabolism caused by deficiency in lysosomal enzyme $\alpha$-glucosidase.

OBJECTIVES: We present first two patients from Slovakia with confirmed Pompe disease.

METHODS: Activity of $\alpha$-glucosidase was measured using 4-methylumbelliferyl- $\alpha$-D- glucopyranoside with the presence of acarbose, inhibitor that eliminates isoenzyme interference of maltase-glucoamylase. This methodical approach is substantial for determination of lysosomal enzyme deficiency. Using molecular genetic methods, PCR-RFLP and direct sequencing of coding region $\alpha$-glucosidase gene (GAA) we have identified causal mutations in our patients. RESULTS: Late-onset type of disease was confirmed by measuring $\alpha$-glucosidase activity in leukocytes isolated from blood. The presence of common Caucasian mutation c.-32-13T>G was proved by genetic testing in the first patient in homozygous state. Second patient was a compound heterozygote, with mutation c. $-32-13 T>G$ on one allele and mutation A486P on the second allele.

CONCLUSION: We present a diagnostic algorithm for diagnosing the Pompe disease in patients of European origin. Enzyme replacement therapy has been used as a treatment option for improving the quality of life of patients. Early diagnosis and treatment of Pompe disease are considered to be critical for maximum efficacy of enzyme replacement therapy (Tab. 1, Fig. 3, Ref. 20). Text in PDF www.elis.sk.

KEY WORDS: Pompe disease, $\alpha$-glucosidase, GAA gene.
\end{abstract}

\section{Introduction}

Pompe disease (glycogen storage disease type II, OMIM\#232300) is an autosomal recessive disorder with estimated incidence 1:40 000 (1). It is caused by deficiency in the lysosomal enzyme acid $\alpha$-glucosidase (EC.3.2.10.20). Accumulation of glycogen in various tissues of the body and impairment of organ function is a consequence of this metabolic disorder.

Pompe disease occurs in forms classified as infantile, juvenile, and adult types based on the onset and clinical presentation of the disorder. Classic infantile form is the most severe of them. Infants develop symptoms within the first months of life, presenting by prominent cardiomyopathy, hypotonia and death before achieving 12 months of life due to cardiorespiratory failure (2). The late-onset forms, referred to as juvenile and adult onsets, have symptoms that are generally limited to skeletal muscle, with a slowly progressive proximal myopathy and marked clini-

${ }^{1}$ Institute of Medical Biology, Genetics and Clinical Genetics, Comenius University Faculty of Medicine, University Hospital Bratislava, Slovakia, ${ }^{2} 2$ nd Department of Paediatrics, Comenius University Faculty of Medicine, University Children's Hospital Bratislava, Bratislava, Slovakia, ${ }^{3}$ Center for Neuromuscular Disorders, University Hospital Bratislava, Bratislava, Slovakia, and ${ }^{4}$ Department of Genetics, Faculty of Natural Sciences, Comenius University in Bratislava, Bratislava, Slovakia

Address for correspondence: S. Mattosova, MD, Institute of Medical Biology, Genetics and Clinical Genetics, Comenius University Faculty of Medicine, University Hospital Bratislava Mickiewiczova 13, SK-813 69 Bratislava, Slovakia.

Phone: +421.2 .57290192$ cal involvement of respiratory muscles. Death usually occurs by respiratory failure $(3,4)$

The gene encoding acid $\alpha$-glucosidase $(G A A)$ is located on chromosome 17q25.2-q25.3 and contains 20 exons, first of which is non-coding (5). The cDNA is over $3.6 \mathrm{~kb}$ in length, with 2,856 nucleotides of coding sequence, predicting a protein of 952 amino acids (6). The enzyme is synthesized as a $110 \mathrm{kDa}$ glycoprotein precursor which is transported to the lysosomal compartment and proteolytically processed into the $95 \mathrm{kDa}$ intermediate and fully active forms of 76 and $70 \mathrm{kDa}$ (7). To date, more than 372 different variations are listed in the Pompe disease mutation database (8). Of these, 250 have been demonstrated to be pathogenic (9). The most frequent mutation in Caucasian late-onset Pompe disease patients is c.-32-13T $>\mathrm{G}$, which gives rise to alternatively spliced transcripts, including a deletion of the first coding exon, but still allows for the production of a low amount (about $10 \%$ ) of normally processed mRNA. This mutation occurs in a heterozygote form in $70-90 \%$ of patients with late-onset Pompe disease $(10,11,12)$.

In 2006, Enzyme replacement therapy (ERT) with recombinant human $\alpha$-glucosidase (aglucosidase alfa, Myozyme, Genzyme) became available. Early initiation of therapy can be life-saving and prevent irreversible muscle damage, emphasizing the need for early diagnosis.

Biochemical and molecular genetic approach was used in the diagnostic scheme of patients with Pompe disease. Two lateonset patients were revealed by selective screening by measuring $\alpha$-glucosidase activity in dried blood spots. The enzyme deficiency was confirmed by measuring $\alpha$-glucosidase activity in mixed 
leukocytes using acarbose as inhibitor of maltase-glucoamylase activity. Based on high prevalence of c.-32-13T $>\mathrm{G}$ mutation in heterozygous form in late-onset Pompe disease patients, we perform the detection of this mutation using PCR-RFLP as a first-step method. Sequencing analysis of the coding region of GAA gene was used for identification of a second mutation. This method is also necessary in case when mutation c.-32-13T $>\mathrm{G}$ is not detected.

\section{Material and methods}

Samples

Samples (whole uncoagulated blood for leukocyte and DNA isolations) were submitted to our laboratory to confirm the diagnosis of Pompe disease in patients in whom the deficiency of $\alpha$-glucosidase was supposed by selective biochemical screening by measuring $\alpha$-glucosidase activity in dried blood spots.

\section{Measurement of $\alpha$-glucosidase activity}

$\alpha$-glucosidase activity was measured according to the method described previously by Okumiya et al (13) using fluorogenic substrate 4-methylumbelliferyl- $\alpha$-D- glucopyranoside (Glycosynth) of final concentration 2 mmol. $^{-1}$ in McIlvain's citrate-phosphate buffer $\mathrm{pH} 4,0$ with $3 \mu \mathrm{mol} .1^{-1}$ acarbose as an inhibitor. Reactions were terminated by $0.2 \mathrm{~mol}^{-1} \mathrm{I}^{-1} \mathrm{Na}_{2} \mathrm{CO}_{3}-\mathrm{NaHCO}_{3}$ buffer; $\mathrm{pH}$ 10.7. Fluorescence was read in a Perkin Elmer fluorimeter (excitation 360, emission 448). The control group with measured $\alpha$-glucosidase activities consisted of 108 samples. In every sample, total activities (uninhibited) and activities in the presence of acarbose (inhibited) were measured. The ratio of acarbose inhibited over uninhibited activity has been calculated.

Protein concentration of samples was determined by Lowry method modified by Hartree (14) using bovine serum albumin as standard.

\section{Molecular analysis}

Identification of c.-32-13T $>$ G mutation

Genomic DNA was isolated from peripheral blood leukocytes using MN NucleoSpin Blood-Mini (Macheray- Nagel). Mutation c.-32-13T $>\mathrm{G}$ was detected by MboII digestion. The amplification primers were described previously (1). The reaction mixture contained 100-150 ng genomic DNA, $100 \mu \mathrm{mol}^{-1}{ }^{-1}$, dNTPs, 1,5 mmol.1 ${ }^{-1} \mathrm{MgCl}_{2}, 0,5 \mu \mathrm{mol} .1^{-1}$ of each primer, $0,625 \mathrm{U}$ Thermo-Start Taq DNA polymerase (Thermo Scientific) in final volume of $25 \mu 1$. The amplification conditions were as follows: initial denaturation at $95{ }^{\circ} \mathrm{C}$ for $15 \mathrm{~min}, 35$ cycles of PCR with each cycle consisting of denaturation for $30 \mathrm{~s}$ at $95^{\circ} \mathrm{C}$, annealing for $30 \mathrm{~s}$ at $63{ }^{\circ} \mathrm{C}$,

Tab. 1. Activity of $\alpha$-glucosidase in late-onset Pompe disease patients and in control group. Activities are expressed in nmol.h.mg ${ }^{-1}$.

\begin{tabular}{lccc}
\hline Patient & $\begin{array}{c}\text { Activity of } \\
\alpha \text {-glucosidase } \\
\text { without acarbose }\end{array}$ & $\begin{array}{c}\text { Activity of } \\
\text {-glucosidase } \\
\text { with acarbose }\end{array}$ & $\begin{array}{c}\text { Ratio } \\
\text { with/without } \\
\text { acarbose }\end{array}$ \\
\hline 1 & 29 & 3 & 0.10 \\
2 & 35 & 8 & 0.24 \\
\hline Control & $37 \pm 14$ & $16 \pm 6$ & $0.42 \pm 0.08$ \\
\hline
\end{tabular}

extension for $30 \mathrm{~s}$ at $72{ }^{\circ} \mathrm{C}$, and the final extension for $10 \mathrm{~min}$ at $72{ }^{\circ} \mathrm{C}$. A volume of $20 \mu \mathrm{l}$ of PCR product and $2.5 \mathrm{U}$ of restriction enzyme were incubated at $37^{\circ} \mathrm{C}$ for $1 \mathrm{~h}$ and fragments were then separated on $2 \%$ agarose gel.

Amplification of $G A A$ gene

The exonic sequences and the flanking intron/exon junctions were amplified by use of primers as described previously (15). The reaction mixture contained $100 \mathrm{ng}$ of genomic DNA, $200 \mu \mathrm{mol} / 1$ dNTPs, $2 \mathrm{mmol} / 1 \mathrm{MgCl}_{2}, 0,3 \mu \mathrm{mol} / 1$ of each primer, $0,625 \mathrm{U}$ GoTaq HotStart polymerase (Promega) in final volume $25 \mu 1$. The amplification conditions were as follows: initiation denaturation $95^{\circ} \mathrm{C}$ for 5 min, 35 cycles of PCR with each cycle consisting of denaturation for $30 \mathrm{~s}$ at $95^{\circ} \mathrm{C}$, annealing for $30 \mathrm{~s}$ (each pair of primers have its own annealing temperature (15)), extension for $1 \mathrm{~min}$ at $72^{\circ} \mathrm{C}$ and final extension for $10 \mathrm{~min}$ at $72^{\circ} \mathrm{C}$. A volume of $10 \mu \mathrm{l}$ of PCR products was run on $2 \%$ agarose gel to verify the amplification. Then, $15 \mu \mathrm{l}$ of PCR products was purified using Fast Alkaline Phosphatase and Exonuclease I before sequencing. The complete coding region of gene was sequenced on ABI Prism 3100 Avant Genetic Analyzer using ABI Prism Big Dye Terminator v3.1 Cycle Sequencing Ready Reaction Kit (Applied Biosystems). All identified mutations were confirmed by sequencing with both forward and reverse primers.

\section{Results}

\section{Patients}

Based on selective screening in dried blood spots, the diagnosis was confirmed in two patients with late-onset type of disease. The first patient, aged 18 years, developed weakness in the girdle and proximal muscle of lower extremities. Myopathic syndrome in upper extremities includes moderate hypertrophy of hypotonic muscles, and mild muscle weakness. Lower extremities showed global muscle weakness, muscle atrophy, positive Trendelenburg sign, "duck" gait, and difficulties arising during squatting or sitting down on a lower chair. Other symptoms include scapular winging and lumbal hyperlordosis. Serum creatin kinase was 19. $9 \mu \mathrm{kat} / \mathrm{l}$.

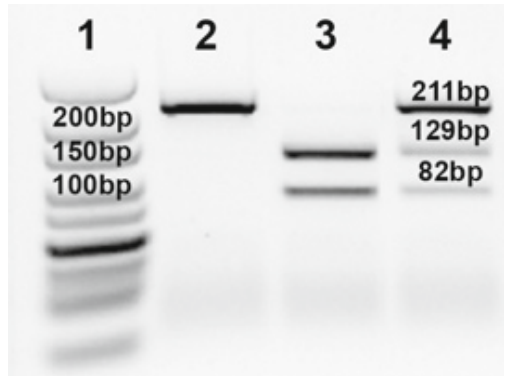

Fig. 1. Demonstration of PCR-RFLP assay. Detection of c. $-32-13 T>G$ mutation by $\mathrm{MboII}$. The present of wild type allele creates an $\mathrm{MboII}$ restriction site. The digestive wild type allele gives rise to 129 and 82 bp restriction fragments. The mutant allele remains undigested (211 bp). Lane 1 shows DNA ladder; lane 2 shows the patient homozygous for c. $-32-13 T>G$ mutation (211 bp product); lane 3 shows healthy individual (homozygous for wild type allele, $129+82$ bp restriction fragments); lane 4 shows the patient heterozygous for c. $-32-13 T>G$ mutation $(211+129+82$ bp restriction fragments). 
A

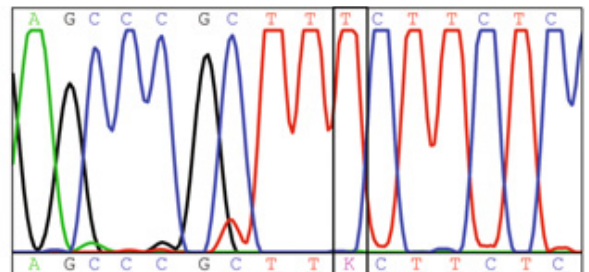

B

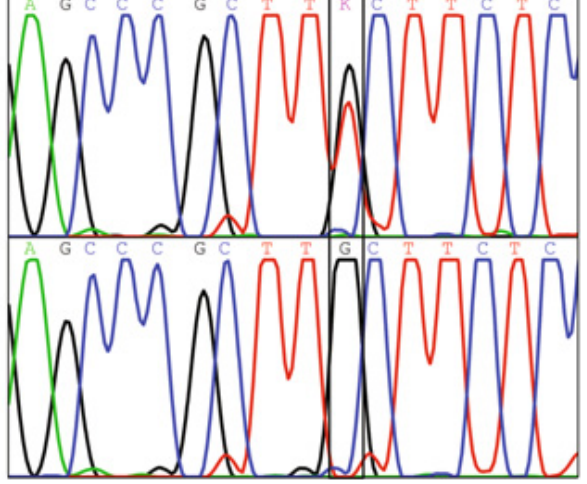

Fig. 2. Sequence analysis of c. $-32-13 T>G$ mutation. A - Patient homozygous for wild type allele. $B$ - Patient heterozygous for c. $\mathbf{- 3 2 - 1 3 T}>G$ mutation. C - Patient homozygous for c. $-32-13 T>G$ mutation.

The second patient, aged 37 years, was observed to have slow development of weakness in the proximal muscles of lower extremities and trunk weakness. This patient presented with a gradually progressing deterioration of walking with dominant limb girdle weakness and scapulae alatae. Serum creatin kinase was $7.7 \mu \mathrm{kat} / \mathrm{l}$.

\section{Biochemical analysis}

By determining acid $\alpha$-glucosidase activity in leukocytes we consider the diagnosis Pompe disease in two patients with lateonset of Pompe disease to be proven with high degree of certainty. The parameter of $\alpha$-glucosidase activities is present in Table 1 . The ratio of enzyme activity (with/without acarbose) in samples was 0.10 and 0.24 , respectively. The ratio of actual control samples were above 0.28 .

\section{Mutation analysis}

Based on high prevalence of c.-32-13T $>\mathrm{G}$ in patients with late-onset type of disease, we performed detection of these mutations in our two patients. In the first patient, we have found this mutation in a homozygous form; in the second patient we have found this mutation only in one allele (Fig. 1). The presence of this mutation was confirmed by sequence analysis (Fig. 2). The sequence analysis in the second patient revealed an A486P mutation in exon 10 on the other allele (Fig. 3).

\section{Discussion}

The diagnosis of Pompe disease in patients with clinical symptoms requires the evidence of $\alpha$-glucosidase activity deficiency. Usually, infants with Pompe disease have activities that are less than $1 \%$ of the mean activity in controls. In older children and adults, the enzyme activity is markedly reduced although residual activity is present. Assay of $\alpha$-glucosidase activity in mixed leukocytes from peripheral blood would be preferred for routine diagnostic practice, but is complicated by the interference of unrelated $\alpha$-glucosidase isoenzymes, most of all by maltase-glucoamylase. For this reason diagnosis based on the measurement of total (uninhibited) activities is not reliable. Without acarbose samples of patients with Pompe disease it could not be discriminated from controls. Acarbose is a potent inhibitor of glucoamylase $(13,16)$. The use of $3 \mu \mathrm{mol} .1^{-1}$ acarbose in solution completely inhibits the maltase-glucoamylase activity in $\mathrm{pH} 4.0$, but the in case of lysosomal $\alpha$-glucosidase only by less than $5 \%$. The presence of acarbose almost eliminated the overlap of the patient and control enzymatic activities, but the discrimination remained poor. One of our patients had activity of $\alpha$-glucosidase in the presence of acarbose $8 \mathrm{nmol} . \mathrm{h} . \mathrm{mg}^{-1}$. This activity is not reliable enough for the diagnosis. Nevertheless, the patient values and control reference values were well separated from each other when the data were expressed as a ratio of activities measured in the presence and absence of acarbose. Therefore, the ratio of in-

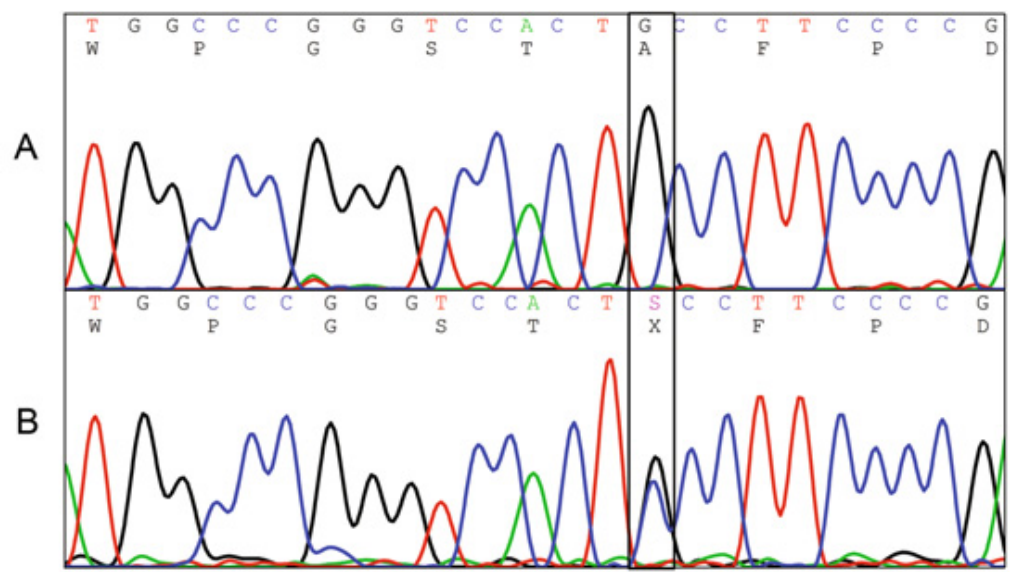

Fig. 3. Sequence analysis of A486P mutation. A - Healthy individual (homozygous for wild type allele). B - Patient heterozygous for A486P mutation (c.1456G $>$ C). 
hibited over uninhibited activity has to be applied as an important criterion for selecting the patients with lysosomal $\alpha$-glucosidase deficiency. According to Okumiya (13), the recommended ratio for controls is $0.48 \pm 0.09$ and for patients with late-onset Pompe disease the ratio is $0.16 \pm 0.02$ (13). The ratio in our patients with late-onset type of disease was 0.10 and 0.24 , respectively. Low reference value for our control group reached 0.28 .

In many countries, the molecular genetic diagnosis in patients with metabolic disorders as well as individual genetic testing for some gene polymorphisms influencing the efficiency of considered pharmacotherapy is a routine approach. This trend has become evident in the past years also in Slovakia $(17,18)$. As a first step in molecular genetic diagnosis of Pompe disease, we use an algorithm with detection of mutation c.-32-13T $>$ G. We have identified this mutation in the first patient in a homozygous form, whereas in the second patient in a heterozygous form. Mutation c.-32-13T $>$ G is identified frequently in European populations and has been detected on at least one allele in over two-thirds of Caucasian patients with late-onset Pompe disease $(10,12,19)$. Despite this common Caucasian mutation, most mutations are rare and limited to individual patients.

Therefore sequence analysis of $G A A$ gene is necessary for final diagnosis. The sequence analysis of the second patient with a heterozygous mutation of c. $-32-13 \mathrm{~T}>\mathrm{G}$ reveals an A486P mutation (c.1456G $>C$ ) in exon 10 on the second allele. This mutation was previouslyreported and has beenclassified as aless severemutation $(8,9,15)$

Pompe disease is a progressive and debilitating disorder that manifests as a continuum of clinical phenotypes that vary with respect to organ involvement, age of onset, and severity. Recently, an enzyme replacement therapy (aglucosidase alfa, Myozyme) became available for Pompe disease patients, allowing treatment and improvement in the quality of life for many patients. The best therapeutic results are achieved when ERT is started early in the course of symptom development and before irreversible muscular damage occurs.

The availability and efficacy of ERT for Pompe disease has required a test to provide rapid diagnosis for treatment to be started as soon as possible. Early diagnosis requires rapid, noninvasive, reliable, and convenient tests. In the past few years, assays on dried blood spots have been developed (20). The measurement of $\alpha$-glucosidase activity in dried blood spots samples provides a reliable, robust method for screening patients for Pompe disease. It should be used as a first-tier test in cases of suspected Pompe disease. It should also facilitate the screening for Pompe disease in adult patients with unclear diagnosis of proximal and limb girdle muscle weakness. Our current experience with laboratory diagnostic of late onset form of Pompe disease support the use of biochemical enzymatic methods combined with molecular genetic methods in patients with unclear cut-off values.

\section{References}

1. Ausems MGEM, Verbiest J, Hermans MMP et al. Frequency of glycogen storage disease type II in The Netherlands: implications for diagnosis and genetic counselling. Eur J Hum Genet 1999; 7: 713-716.

2. van den Hout HMP, Hop W., van Diggelen OP et al. The natural course of infantile Pompe's disease: 20 original cases compared with 133 cases from the literature. Pediatrics 2003; 112: 332-340.
3. Winkel LPF, Hagemans MLC, van Doorn PA, Loonen MCB, Hop WJC, Reuser AJJ, van der Ploeg AT. The natural course of non-classic Pompe's disease; a review of 225 published cases. J Neurol 2005; 252: 875-884.

4. Hagemans MLC, Winkel LPF, Van Doorn PA, Hop WJC, Loonen MBC, Reuser AJJ, Van der Ploeg AT. Clinical manifestation and natural course of late-onset Pompe's disease in 54 Dutch patients. Brain 2005; 128: 671-677.

5. Hoefsloot LH, Hoogeveen-Westerveld M., Reuser AJ, Oostra BA. Characterization of the human lysosomal alpha-glucosidase gene. Biochem J 1990; 272: 493-497.

6. Martiniuk F, Mehler M, Tzall S, Meredith G, Hirschhorn R. Sequence of the cDNA and 5 '-flanking region for human acid alpha-glucosidase, detection of an intron in the 5 'untranslated leader sequence, definition of 18 bp polymorphisms, and differences with previous cDNA and amino acid sequences. DNA Cell Biol 1990; 9 (2): 85-94.

7. Moreland RJ, Jin X, Zhang XK et al. Lysosomal Acid $\alpha$-glucosidase consist of four different peptides processed from a single precursor. J Biol Chem 2005; 280 (8): 6780-6791.

\section{8. http://www.pompecenter.nl.}

9. Kroos M, Hoogeveen-Westerveld M, Michelakakis $\mathrm{H}$ et al. Update of the Pompe disease Mutation database with 60 novel sequence variants and additional studies on the functional effects of 34 previously reported variants. Hum Mutat 2012; 33 (8): 1161-1165.

10. Huie ML, Chen AS, Tsujino S, Shanske S, DiMauro S, Engel AG, Hirschhorn R. Aberrant splicing in adult onset glycogen storage disease type II (GSDII): molecular identification of an IVS1 $(-13 \mathrm{~T} \rightarrow \mathrm{G})$ mutation in a majority of patients and a novel IVS10 $(+1 \mathrm{GT} \rightarrow \mathrm{CT})$ mutation. Hum Mol Genet 1994; 3 (12): 2231-2236.

11. Boerkoel CF, Exelbert R, Nicastri C, Nichols RC, Miller FW, Plotz PH, Raben N. Leakly splicing mutation in the acid maltase gene is associated with delayed onset of glycogenosis type II. Am J Hum Genet 1995; 56: 887-897.

12. Joshi PR, Gläser D, Schmidt $S$ et al. Molecular diagnosis of German patients with late-onset glycogen storage disease type II. J Inher Metab Dis 2008; 31: S261-S265.

13. Okumiya T, Keulemans JLM, Kroos MA et al. A new diagnostic assay for glycogen storage disease type II in mixed leukocytes. Mol Genet Metab 2006; 88: 22-28.

14. Hartree EF. Determination of protein: a modification of the Lowry method that gives a linear photometric response. Anal Biochem 1972; 48: 422-427.

15. Oba-Shinjo SM, da Silva R, Andrade FG et al. Pompe disease in a Brazilian series: clinical and molecular analyses with identification of nine new mutations. J Neurol 2009; 256 (1): 1881-1890.

16. Li Y, Scott CR, Chamoles NA, Ghavami A, Pinto BM, Turecek F, Gelb MH. Direct multiplex assay of lysosomal enzymes in dried blood spots for newborn screening. Clin Chem 2004; 50: 1785-1796.

17. Radvanszky J, Surovy M, Polak E, Kadasi L. Uninterrupted CCTG tracts in the myotonic dystrophy type 2 associated locus. Neuromuscul. Disord 2013; 23 (7): 591-598.

18. Desatova B, Hlavaty T, Balakova D et al. Prevalence of mutations in thiopurine S-methyltransferase gene among Slovak IBD patients. Bratisl Lek Listy 2013; 114 (6): 330-332.

19. Montalvo ALE, Bembi B, Donnarumma $M$ et al. Mutation profile of the $G A A$ gene in 40 Italian patients with late onset glycogen storage disease type II. Hum Mutat 2006; 27: 999-1006.

20. Chamoles NA, Niizawa G, Blanco M, Gaggioli D, Casentini C.o Glycogen storage disease type II: enzymatic screening in dried blood spots on filter paper. Clin Chim Acta 2004; 347: 91-102.

Received August 13, 2014. Accepted October 6, 2014. 